\title{
An effective step for evaluating of the sexual function: Developing and Standardizing Sexual Intelligence Scale
}

Mahnaz Aliakbari Dehkordi

Payame Noor University

Azita Kharaman ( $\square$ azitakharaman99@gmail.com )

Payame Noor University

Tayebeh Mohtashami

Shahrood university of medical sciences

Zahra Karimi

Payame Noor University

\section{Research Article}

Keywords: Sexual Intelligence, standardizing scale, Iranian population

Posted Date: September 27th, 2021

DOl: https://doi.org/10.21203/rs.3.rs-737465/v2

License: (c) (i) This work is licensed under a Creative Commons Attribution 4.0 International License. Read Full License 


\section{Abstract \\ Background}

Sexual intelligence is one of the most vital topics in research and clinical fields. Therefore, the existence of a suitable instrument for measuring these structures is an inevitable necessity. This study designed a valid and reliable sexual intelligence scale.

\section{Methods}

In this instrumental research, 225 students of Payame Noor University were selected by purposeful sampling and answered the questionnaire. A baseline questionnaire with 36 questions was provided to the participants. SPSS software, statistical analysis of factor analysis and correlation coefficient were used for data analysis.

\section{Results}

In an exploratory factor analysis that was done on 19 materials of this test, results revealed 4 factors. Initial examination in this test showed that 4 important and prominent factors were found after rotation and by considering the sloping line diagram.

\section{Conclusion}

The present study showed that the designed tool is of sufficient competence and can be used in clinical research and diagnosis.

\section{Introduction}

All humans need to communicate with others. Communication and relation with others mean sharing, sympathy, and intimacy, and intimacy in physical terms means sexual pleasure(1).

The depth of intimacy which two persons make in their relationship depends on their ability in clear, correct, and effective transfer of thoughts, feelings, needs, wishes, and wants (2).

Sexual intelligence facilitates the correct transfer of thoughts and feelings, accelerates this learning and makes real the definition of Piaget (1950) for intelligence which is based on a certain form of consistency between person and environment (3). Indeed, intelligence assessment reminds persons of the advantages, limitations, or performance of their sexual partner to adjust the relationship with themselves not adjust them with the relationship (4). 
Sexual relationship is not just an activity but is an idea and the ideas of the person in this regard are so complex that activity in this regard will seem complex. However, sexual intelligence should decrease the complexity of activity and ideas to make a more pleasant and easier relationship. In other words, sexual intelligence can help persons to grow, to have new sexual experiences, to change their ideas in this regard, and to enjoy their sexual relationship with new insight (5).

Sexual intelligence is composed of three components which are: information and knowledge; emotional skills; and insights related to the body and its comfort (5). The knowledge that most people consider is how to do sex with my partner correctly? How to get rid of sexual dysfunction? However, thinking about these objectives is wrong and answer to these questions is not an effective way to make a pleasant relationship. Moreover, most of the skills required for making a pleasant relationship are not necessarily sexual and emotional skills are necessary for satisfaction in most parts of life and especially sexual life. If persons only expected sexual pleasure from the relationship, it could be said that only physical skills and physiologic knowledge are required. However, as it was mentioned, psychological satisfaction is also expected from the sexual relationship in which emotional skills should not be ignored to achieve this. Finally, body sexual intelligence theory is being considered as a means for adjusting to partner and this factor increases body tolerance for sexual pleasure. However, the body can't be forced to do a certain type of performance. Self-esteem, trust, and self-knowledge borders are among important aspects of sexual intelligence. The excellent and perfect relationship is not considered in this theory and physical characteristics and special techniques will not be included (5). Practically, sexual intelligence is a new method for changing views of persons toward sex for them to not purse normal sex. However, many persons don't satisfy with such conditions, including total hygiene, total health, being romantic, not being worried for orgasm, and so on (6).

Indeed, most persons don't want to be abnormal in sexual terms. Thus, they hide their sexual issues that think are abnormal. They focus on things that think are normal, even if they don't like them. This will cause problems which are resulted from hiding, stress and anxiety, self-critic, and boredom. If persons wanted intimate and total relationship instead of passion for the normal relationship which causes stress and controlled orgasm or ejaculation, they could easily have a pleasant relationship. What is, in fact, important in sex is not things that can be measured, but is the feeling of the person which is hard to assess, understand, test, or stabilize. It can be said that sexual intelligence based on self-knowledge, selfacceptance, and deep relationship is a better method than prescribing solutions for lack of satisfaction, because they will say the person to have which type of relationship and also describe its manner and time which this method is not effective and push persons toward sexual treatments and finally cause them not to be themselves in the relationship which results in anxiety and lack of sexual satisfaction. We should try sexual instructions to provide couples with a comprehensive map for them to be able to improve their sexual performances in all times and places. Moreover, sexual life needs its special behavior and conditions at any age and common instructions only provide a general framework for an ideal relationship (5). 
It can be concluded that a single approach cannot be used for instructions related to different couples with different cultures and characteristics and even providing information on sexual differences cannot be effective and couples should find their special method for their special relationship by considering all aspects of their life. Sexual intelligence is a comprehensive view of sexual life in which cultural differences don't affect it (5).Sexual intelligence provides this framework for them by emphasizing on self-construction, realizing the feelings, self-knowledge, and self-acceptance (5) which provides intimacy in the life of couples and improves their sexual performance (1), thus, making a sexual intelligence scale can be useful in instruction and research.

In recent years, sexual issues have received the attention of researchers and different tools have been designed to assess sexual performance, including questionnaires designed by Rosen et al.(7), Fallis, Bordon, and Rahman (8), Basson.(9), Frost and Donovan(10), Kim et al.(11), and questionnaire in Iran including Besharat \& Ranjbar Kalagari (12).

However, it can be said that treatment or promotion intervention on sexual performance in Iran is not very old and limited studies have been done in this regard. It seems that conducting studies consistent with Iranian-native culture can be useful in resolving sexual problems in different socioeconomic groups and keeping family health (13). Lack of knowledge on sexual issues can result in an unpleasant life, divided family, divorce, deviation, and psychological problems (1). Incorrect sexual performances in couples can result from a lack of sexual knowledge, sexual skills, and relationship skills (14). Sexual intelligence provides people with the power to make a change in their life and their way of thinking about sex (15).

Concerning the importance and necessity of doing a study on sexual intelligence and measuring its aspects and elements to make it practical and enter it in real and operational aspects of life despite making theories on sexual intelligence and doing qualitative studies in this regard in psychology, this question is being formed that what we can do for measuring and operationalizing sexual intelligence concept? In other words, the current study aims to design and specify a quantitative scale, fitness of model test, and psychological; adequacy test of this scale to convert sexual intelligence concept into quantitative measures. Therefore, the current study seeks to answer this question that whether a reliable and valid tool can be prepared for measuring the sexual intelligence of persons?

\section{Method}

Research design: the current research is a descriptive study with a testing approach. Statistical population: The statistical population of the current study is students of the Payam Noor University of Tehran at undergraduate, graduate, and Doctoral degrees which 225 students (191 women and 25 men) were selected by cluster random sampling method. The sample size was based on this belief that at least 200 persons are required to do factor analysis on data (16).

In this regard, Palant (17) believes that the sample size should be more than 150 participants and 5 participants for each item or question ratio should be observed. At the time of recruitment, participants were informed about the study goals, the confidential situation of interviews, secure data handling, and 
their voluntary participation. Then informed consent was obtained. Questionnaires were designed anonymous for observing ethical considerations and participants were informed that their information is confidential and will be used in a study. Inclusion criteria were personal consent, being married, and a lack of physical and psychological problems that require drug use.

\section{Steps of making scale}

\section{Step 1}

After determining and planning the subject of the scale, the definition of its borders and examination of sexual intelligence characteristics was done based on theoretical studies and consulting with experts.

Step 2: concerning theoretical foundations and comments of experts, a questionnaire with 36 items was prepared. Sexual intelligence has three components: information, emotional skills, body knowledge. In this scale, questions 1 to 12 reveal details of the information. This component contains the following concepts: body anatomy and physiology, sexual response cycle, orgasm, prevention from pregnancy, infections transferred by sex, coming from Mars-Venus or Earth, and various methods of sex. Questions 12 to 24 reveal details of emotional skills. The emotional skills component contains the following factors: self-acceptance, trust, communications, keeping sexual respect when facing disappointment, conformityharmony. Questions 24 to 36 reveal details of body knowledge. This component contains the following concepts: sixth sense or three-dimensional radar which includes inner understanding and kinetic knowledge; complexities related to touch and cares; trusting body, determining borders.

When examining the validity of the questionnaire, 2 items were removed and some items were corrected and edited.

\section{Step 3}

a questionnaire was implemented on some students during collecting and analyzing information and 15 questions were removed about the low correlation coefficient with other questions.

Finally, a questionnaire with 19 questions with a 5 point Likert scale (very high $=5$, high $=4$, moderate $=3$, low $=2$, very low $=1$ ) was made and standardized for assessing sexual intelligence in Iranian student population.

\section{Data analysis method}

in current research, descriptive and inferential statistics including reliability, construct validity, and factor validity was used. Data were analyzed by SPSS24 software and LISREL 8.5 software.

\section{Results}


Various forms of validity and reliability were used to examine psychometric characteristics. Cronbach's alpha was used for examining reliability, and content validity, construct validity, and factor validity were used to examine the validity of the questionnaire.

Content validity: is a type of validity that is usually used to measure elements of the contents of a measurement tool. In order to validate the sexual intelligence scale, the questionnaire was prepared by using various resources. Then, it was given to eight professors of the psychology department to assess its content validity.

Factor validity: is a type of validity that is obtained from the factor analysis. In order to examine factor validity and since this questionnaire was made for the first time and is being used for the first time in Iran, the exploratory factorial analysis was used.

In the exploratory factor analysis method, the Scree test and Varimax aggressive rotation method were used and four factors were obtained concerning results of significance level ( $p=0.0001)$, Kaiser-MeyerOlkin Measure (KMO = 0.727), and Croat-Bartlett test (Bts = 989.84). Results of the exploratory factor analysis showed that a sexual intelligence questionnaire is made of four factors in which the value of specified variance has been estimated for all factors which specify 49.18 of the total variance. The results are presented in Table 1. In order to decide on extracting which factor, a scree plot can be used (Fig. 1).

Table 1

Results of exploratory factor analysis for sexual intelligence questionnaire.

\begin{tabular}{|llll|}
\hline Factor & Total & \% of Variance & Cumulative \% \\
\hline First & 4.26 & 22.46 & 22.46 \\
\hline Second & 2.28 & 12.02 & 34.48 \\
\hline Third & 1.65 & 8.7 & 43.19 \\
\hline Forth & 1.14 & 5.99 & 49.18 \\
\hline
\end{tabular}

Table 1. Results of exploratory factor analysis for sexual intelligence questionnaire.

Figure 1. Scree plot.

Table 2. Rotated factor loading of sexual intelligence questionnaire. 
Table 2

Rotated factor loading of sexual intelligence questionnaire.

\begin{tabular}{|lllll}
\hline Question & First factor & Second factor & Third factor & Forth factor \\
\hline 6 & 0.544 & & & \\
\hline 13 & 0.537 & & & \\
\hline 15 & 0.515 & & & \\
\hline 3 & 0.803 & & & \\
\hline 4 & & 0.779 & & \\
\hline 10 & & 0.523 & & \\
\hline 16 & 0.459 & & 0.615 \\
\hline 18 & & 0.539 & & \\
\hline 19 & & 0.679 & & \\
\hline 5 & & 0.757 & 0.683 & \\
\hline 8 & & & 0.562 & \\
\hline 9 & & & 0.698 & \\
\hline 12 & & & & \\
\hline 1 & & & & \\
\hline 2 & & & & \\
\hline 7 & & & & \\
\hline 11 & & & & \\
\hline 17 & & & & \\
\hline
\end{tabular}

As it can be seen in Table 2 and based on exploratory factor analysis, 4 questions loaded on the first factor (touch, cares, the comfort of the body), 6 questions loaded on the second factor (determining borders), 4 questions loaded on the third factor (trust and communications), and 5 questions loaded on the fourth factor (orgasm and hygiene).

In order to confirm the factorial structure obtained and testing the power and significance of each factor in measuring the sexual intelligence questionnaire, the confirmatory factor analysis was done by using LISREL software which was prepared by Jursgak and Sorbum (1984) for testing various patterns of measuring. Table 3 presents the measurement parameters. 
Table 3

Goodness-of-fit indices for measuring patterns in all subjects of research $(n=225)$.

\begin{tabular}{|ll|}
\hline Statistic & Goodness-of-fit index \\
\hline$\chi^{2} / \mathrm{df}$ & 1684.81 \\
\hline $\mathrm{RMSEA}^{1}$ & 0.051 \\
\hline $\mathrm{SRMR}^{2}$ & 0.067 \\
\hline $\mathrm{GFI}^{3}$ & 0.88 \\
\hline $\mathrm{AGFI}^{4}$ & 0.86 \\
\hline $\mathrm{CFI}^{5}$ & 0.90 \\
\hline $\mathrm{IFI}^{6}$ & 0.89 \\
\hline $\mathrm{NFI}^{7}$ & 0.89 \\
\hline 1.Root Mean Square Error of & Approximation 2. Standardized Root Mean Square Residual \\
\hline 3. Goodness of Fit Index 4. Adjusted Goodness of Fit Index 5. Comparative Fit Index \\
\hline 6. Incremental Fit Index 7. Normed Fit Index \\
\hline
\end{tabular}

Table 3. Goodness-of-fit indices for measuring patterns in all subjects of research $(n=225)$.

As can be seen in Table 3, the value of approximate mean error root index and remainder mean squares root index was standardized which is related to the remainder of the model is fluctuating between 0 and 1 and the lower value shows more fit. When the value of this statistic is lower than 0.06 , the model has an acceptable fit. Since these indices were 0.051 and 0.067 in current research, it can be said that the model is fit. The values of the goodness-of-fit index, mediated goodness-of-fit index, adaptive fit index, increasing fit index, and standardized fit index are fluctuating between 0 and 1 . The higher this value, the more fit of the model. When the value of this statistic is higher than 0.9 , the model is fit. Since these indices in current research are $0.88,0.86,0.90,0.89$, and 0.89 , respectively; it can be said that the model has an acceptable fit. Figure 2 shows the structure of the confirmatory factor analysis.

\section{Figure2. Structural diagram of factor analysis of sexual intelligence scale}

Construct validity: to examine construct validity and internal consistency of the sexual intelligence questionnaire and its components, correlation coefficients between sub-scales and total score were calculated which results are shown in Table 4. 
Table 4

Correlation matrix of the total score of sexual intelligence questionnaire and its components.

\begin{tabular}{|llllll|}
\hline & Variable & $\begin{array}{l}\text { Touch, cares and } \\
\text { body comfort }\end{array}$ & $\begin{array}{l}\text { Determining } \\
\text { borders }\end{array}$ & $\begin{array}{l}\text { Trust and } \\
\text { communication }\end{array}$ & $\begin{array}{l}\text { Orgasm } \\
\text { and body } \\
\text { health }\end{array}$ \\
\hline $\begin{array}{l}\text { Sexual } \\
\text { intelligence }\end{array}$ & $\begin{array}{l}\text { Pearson } \\
\text { correlation } \\
\text { coefficient }\end{array}$ & $* * 0.725$ & $* * 0.743$ & $* * 0.7$ & $0.652 \star *$ \\
\hline $\begin{array}{l}\text { Statistical } \\
\text { significance }\end{array}$ & 0.0001 & 0.0001 & 0.0001 & 0.0001 \\
\hline
\end{tabular}

Table 4. Correlation matrix of the total score of sexual intelligence questionnaire and its components.

As can be seen in Table 4, all components of sexual intelligence have a significant relationship with the total score of this scale. Correlation coefficients pattern in Table 4 shows that there are good internal relationships among components.

To estimate the reliability of sexual intelligence questionnaire, Cronbach's alpha was used. The results are presented in Table 5.

Table 5

The number of questions and amount of internal consistency (Cronbach's alpha) for each factor and the whole questionnaire.

\begin{tabular}{|lll|}
\hline Factor & The number of questions & Cronbach's alpha \\
\hline Touch, cares and body comfort & 4 & 0.741 \\
\hline Determining borders & 6 & 0.723 \\
\hline Trust and communication & 4 & 0.749 \\
\hline Orgasm and body health & 5 & 0.759 \\
\hline The whole scale & 19 & 0.71 \\
\hline
\end{tabular}

Table 5. The number of questions and amount of internal consistency (Cronbach's alpha) for each factor and the whole questionnaire.

As can be seen in Table 5, the whole scale and its components have good reliability.

Mean, mode, and standard deviation were used to measure Iranian norms. The results are presented in Table 6. Moreover, tables of percentile norms were used and standardized score ( $\mathrm{Z}$ ) and T-scores were presented for each factor. 
Table 6

Descriptive indices of scores of sexual intelligence factors for research subjects $(n=225)$.

\begin{tabular}{|llll|}
\hline Factors & Mean & Standard deviation & Mode \\
\hline Touch, cares and body comfort & 15.6 & 2.75 & 15 \\
\hline Determining borders & 18.76 & 4.04 & 19 \\
\hline Trust and communication & 14.75 & 2.67 & 15 \\
\hline Orgasm and body health & 19.35 & 2.95 & 20 \\
\hline Sexual intelligence & 67.93 & 8.85 & 68 \\
\hline
\end{tabular}

Table 6. Descriptive indices of scores of sexual intelligence factors for research subjects $(n=225)$.

As can be seen in Table 6, scores of mean, standard deviation, and mode have been reported in the sexual intelligence questionnaire and its four components.

Moreover, ranking each one of the factors can be examined by using the normal curve which can be seen in Fig. 3, and scores of the mean and standard deviation of each factor of sexual intelligence. The results are presented in Table 7.

Table 7

Values of standard scores in sexual intelligence.

\begin{tabular}{|llllll|}
\hline Factor & Very strong & strong & medium & weak & Very weak \\
\hline Touch, cares and body comfort & $20-23$ & $16-19$ & $12-15$ & $8-11$ & $4-7$ \\
\hline Determining borders & $28-33$ & $22-27$ & $16-21$ & $10-15$ & $4-9$ \\
\hline Trust and communication & $20-23$ & $16-19$ & $12-15$ & $8-11$ & $4-7$ \\
\hline Orgasm and body health & $14-29$ & $19-23$ & $14-18$ & $9-13$ & $4-7$ \\
\hline Sexual intelligence & $83-98$ & $67-82$ & $51-66$ & $35-50$ & $19-34$ \\
\hline
\end{tabular}

Figure 3. Normal distribution curve

Table 7. Values of standard scores in sexual intelligence.

As can be seen in Table 7, each one of sexual intelligence factors has been converted to standard scores on a five-point Likert scale from very high to very low. Generally, the lowest score in sexual intelligence is 19 and the highest score is 95.

The following table, 8 , shows the percentile rank $\left(P_{10}-P_{9}\right)$ of raw scores and types of standard scores. 
Table 8. Percentile rank $\left(P_{10}-P_{9}\right)$ of raw scores, standardized score, and T-scores of sexual intelligence factors.

Table 8

Percentile rank $\left(\mathrm{P}_{10}-\mathrm{P}_{9}\right)$ of raw scores, standardized score, and T-scores of sexual intelligence factors.

\begin{tabular}{|c|c|c|c|c|c|c|c|c|c|c|}
\hline \multirow[t]{2}{*}{ Factor } & \multirow[t]{2}{*}{ Type of score } & \multicolumn{9}{|c|}{ Percentile rank } \\
\hline & & 10 & 20 & 30 & 40 & 50 & 60 & 70 & 80 & 90 \\
\hline \multirow[t]{3}{*}{1} & Raw score & 11 & 13 & 14 & 15 & 15 & 16 & 17 & 17 & 19 \\
\hline & $\begin{array}{l}\text { Standardized } \\
\text { score }\end{array}$ & -1.45 & -0.738 & -0.38 & -0.02 & -0.02 & 0.33 & 0.69 & 0.69 & 1.4 \\
\hline & T- score & 35.5 & 42.7 & 46.2 & 49.8 & 49.8 & 53.3 & 56.9 & 56.9 & 64 \\
\hline \multirow[t]{3}{*}{2} & Raw score & 14 & 15 & 16 & 18 & 19 & 20 & 21 & 22 & 24 \\
\hline & $\begin{array}{l}\text { Standardized } \\
\text { score }\end{array}$ & -1.17 & -0.92 & -0.68 & -0.18 & 0.05 & 0.3 & 0.55 & 0.8 & 1.29 \\
\hline & T- score & 38.3 & 40.8 & 43.2 & 48.2 & 50.5 & 53 & 55.5 & 58 & 62.9 \\
\hline \multirow[t]{3}{*}{3} & Raw score & 11 & 13 & 13 & 14 & 15 & 15 & 15 & 17 & 18 \\
\hline & $\begin{array}{l}\text { Standardized } \\
\text { score }\end{array}$ & -1.4 & -0.65 & -0.65 & -0.28 & 0.09 & 0.46 & 0.46 & 0.84 & 1.21 \\
\hline & T- score & 38.6 & 43.5 & 43.5 & 47.2 & 50.09 & 54.6 & 54.6 & 58.4 & 62.1 \\
\hline \multirow[t]{3}{*}{4} & Raw score & 15 & 17 & 18 & 19 & 20 & 20 & 21 & 22 & 23 \\
\hline & $\begin{array}{l}\text { Standardized } \\
\text { score }\end{array}$ & -1.45 & -0.78 & -0.45 & -0.11 & 0.21 & 0.21 & 0.55 & 0.88 & 1.22 \\
\hline & T- score & 35.5 & 42.2 & 45.5 & 48.9 & 52.1 & 52.1 & 55.5 & 58.8 & 62.2 \\
\hline \multirow[t]{3}{*}{5} & Raw score & 57 & 60 & 63 & 66 & 68 & 70 & 73 & 76 & 80 \\
\hline & $\begin{array}{l}\text { Standardized } \\
\text { score }\end{array}$ & -1.23 & -0.89 & -0.55 & -0.21 & -0.007 & 0.23 & 0.57 & 0.91 & 1.36 \\
\hline & T- score & 37.7 & 41.1 & 44.5 & 47.9 & 49.93 & 52.3 & 55.7 & 59.1 & 63.6 \\
\hline
\end{tabular}


Table 9

Sexual Intelligence Questionnaire (2020).

$\begin{array}{lll}\text { No Expression } & \begin{array}{c}\text { Very } \\ \text { high }\end{array} & \text { High Moderate Low Very } \\ & \text { low }\end{array}$

1 Form my view, reaching orgasm is an inseparable part of sex.

2 I think that my partner should be best in all terms, so I can enjoy having sex with him/her.

3 Judgments and beliefs that society determines for sex are very important to me.

$4 \quad$ I use standards and information that experts say about sex.

5 I always follow my attitude and fantasies about sex.

6 I enjoy all parts of my partner during sex.

7 I always expect to reach orgasm in sex.

8 I pay attention to the emotional relationship with my partner in times other than sex.

$9 \quad$ I think about trust during sex.

10 I think that I should do everything right and perfect during sex.

11 Having sex is a good way to make intimacy between me and my partner.

12 I enjoy having sex even if I don't achieve what I wanted.

13 I try to keep a sense of humor during sex.

14 I pay attention to conform to my body and my partner's body during sex.

15 I try to have sex with my partner whenever I feel he/she needs sex.

16 I always pay attention to my partner's limitations and selections during sex.

17 It is very important to me that my body or my partner's body doesn't have a bad smell during sex.

18 I think about anything I want to do during sex. 
Table, 9, is the Designed Sexual Intelligence Questionnaire by Aliakbari et al included 18 questions with a five-point Likert scale from very high to very low.

\section{Discussion}

Sexual intelligence is one of the important subjects in sexual psychology. However, reviewing literature in this regard revealed that most of the studies are about theoretical discussions and no significant try has been done for making this concept practical and use it in experimental research and also in clinical diagnoses. Thus, the main purpose of the current study was to design a tool for measuring sexual intelligence. To do this, aspects of sexual intelligence were first defined in terms of three components (information and knowledge, emotional skills, and insights on the body and its comfort) with regard to theoretical discussions. Then, questions of this scale were prepared and given to participants by using fundamental definitions in these three conceptual areas. In an exploratory factor analysis that was done on 19 materials of this test, results revealed 4 factors. Initial examination in this test showed that 4 important and prominent factors were found after rotation and by considering the sloping line diagram and the value more than 1 which these factors form 48.34 of variance. The first factor which is "touch, cares, and body comfort", is composed of 4 items in which the factor loading of its questions is fluctuating between 0.35 and 0.69 . This factor contains items on information and knowledge on the body. Information and knowledge on sexual issues changes and improve life and insufficient information and incorrect sexual believes of couples are among prevalent psychological factors in action-sexual disorders (18). Accurate information is among the important necessities in making correct decisions.

The second factor which is "determining borders", is made of 6 items and the factor loading of its questions is fluctuating between 0.41 and 0.72 . This factor contains determining personal borders in sex and judging them. Generally, sexual satisfaction is judgment and analysis of sexual behavior (19) .Therefore, identical sexual activity can have different meanings for different persons and even change from a period to another (20).

The third factor which is "trust and communications" is composed of 4 items and the factor loading of items is fluctuating between 0.47 and 0.73 . This factor is related to trust between couples. There are various factors which should be trusted in sex like enjoying safety, sex without abuse, trusting partner when he/she speaks of stimulation and satisfaction. Trusting self will result in a trusting partner. Lack of trust and a sense of cheating results in critics and stress and this is among the most important problems in matrimonial relationships (5). Emotional failure is one of the influential resources on matrimonial satisfaction (21).

The fourth factor which is "orgasm and body health" is made of 5 items and the factor loading of items is fluctuating between 0.37 and 0.66 . This factor is related to body feelings during sex. Lalumiere et al, (22) were the first who systematically studied human behaviors. They stated that sexual components are sexual desire, stimulation, orgasm, and subsidence. Studies reveal that better orgasm is consistent with sexual satisfaction and keeping the passion for sex (23). 
It can be said that sexual performance is like a cycle that various biological and psychological factors or internal and external factors affect it (24). Sexual intelligence is related to different factors, such that matrimonial quality is confused with other variables of sex (25). Matrimonial satisfaction from Hockings' view is defined when all aspects of marriage are being considered (26). In fact, it can be said that matrimonial satisfaction is a positive and pleasant attitude which is considered and assessed from different aspects.

It can be said that the adequacy of a measurement scale depends on factors such as technical characteristics of sub-scales, reliability, validity, and practicality of them (27). Technically, sub-scales of this questionnaire have a relatively low number of questions which facilitates implementing scale by the researcher. Results of data analysis showed that a designed scale has good reliability and validity and can provide an acceptable and valid picture of this construct. Therefore, it can be used to assess the sexual intelligence of people. Validity is the most important characteristic when using a scale. In the current research, content validity was used. This validity states that materials or contents of scale present characteristics that will be measured (28). It can be concluded that this scale has good content validity. Moreover, the factorial structure of this scale is consistent with its theoretical structure is the most important index for confirming the construct validity of this scale. When examining the factorial validity of the scale, the confirmatory factor analysis was used in which the results reveal a good fit of the model in determining the factors.

Mean, mode, and standard deviation were used to Iranian standards along with tables of percentile norms and standardized scores ( $\mathrm{Z}$ ) and T-scores. Thus, this scale was converted to standard scores and has Iranian standards.

Results of current research confirmed reliability, validity, and factorial structure of the sexual intelligence scale; however, the current study has limitations for being a preliminary study. These limitations are especially obvious in examining types of the validity of a scale which is a continuous process. Thus, it is recommended that research designs will be prepared for complementing the process of validating the sexual intelligence scale and even repeating some studies to confirm current findings. Another limitation of the current study is about psychometric characteristics of the sexual intelligence scale and research population that is a sample of the general population which is students. Thus, these results should be considered preliminary, especially in terms of factor analysis of sexual intelligence analysis. Therefore, current research is the first try to prepare a tool for measuring sexual intelligence and more studies should be done in this regard. It is recommended that the reliability and validity of this scale are examined in groups other than students.

\section{Declarations}

Funding: This study was not funded by anywhere.

Conflict of Interest: The authors declare that they have no conflict of interest. 
Ethics approval: Approval was obtained from the ethics committee of Payame noor University. The procedures used in this study adhere to the tenets of the Declaration of Helsinki.

Consent to participate: All participants were aware about study conditions and they were able to give up their collaboration in any step of study.

Consent for publication: The current manuscript has never published in elsewhere and all authors are satisfied with publish their manuscript in the journal of BMS Family Practice.

Availability of data: All data used is available.

Code availability: No applicable

Author contributions: All authors contributed to the study conception and design. Material preparation, data collection and analysis were performed by Mahnaz Aliakbari Dehkordi, Azita Kharaman, and Tayebeh Mohtashami. The first draft of the manuscript was written by Tayebeh Mohtashami and Zahra Karimi and all authors commented on previous versions of the manuscript. All authors read and approved the final manuscript.

\section{References}

1. Kardan-Souraki M, Hamzehgardeshi Z, Asadpour I, Mohammadpour RA, Khani S. A review of marital intimacy-enhancing interventions among married individuals. Global journal of health science. 2016;8(8):74.

2. Bagarozzi DA. Enhancing intimacy in marriage: A clinician's guide. routledge; 2014.

3. Groth-Marnat G. Handbook of psychological assessment. John Wiley \& Sons; 2009.

4. Earle MR. A Review on Sexual Intelligence: What We Really Want from Sex and How to Get It. Taylor \& Francis; 2012.

5. Klein M. Sexual Intelligence: What We Really Want from Sex-and how to Get it. Harper Collins; 2012.

6. van't Noordende AT, van Brakel WH, Banstola N, Dhakal KP. The impact of leprosy on marital relationships and sexual health among married women in eastern Nepal. Journal of tropical medicine. 2016;2016.

7. Rosen J. Heiman, S. Leiblum, C. Meston, R. Shabsigh, D. Ferguson, R. D'Agostino, R CB. The Female Sexual Function Index (FSFI): a multidimensional self-report instrument for the assessment of female sexual function. Journal of sex \& marital therapy. 2000;26(2):191-208.

8. Fallis EE, Rehman US, Purdon C. Perceptions of partner sexual satisfaction in heterosexual committed relationships. Archives of sexual behavior. 2014;43(3):541-50.

9. Basson R. The female sexual response: A different model. Journal of Sex \&Marital Therapy. 2000;26(1):51-65. 
10. Frost $R$, Donovan $C$. The development and validation of the sexual and relationship distress scale. The journal of sexual medicine. 2018;15(8):1167-79.

11. Kim JJ, Horne RM, Muise A, Impett EA. Development and validation of the responses to sexual rejection scale. Personality and Individual Differences. 2019;144:88-93.

12. BESHARAT MALI, RANJBAR KE. Development and validation of sexual knowledge and attitude scale. 2013;

13. Ahmadnia E, Haseli A, Karamat A. Therapeutic interventions conducted on improving women's sexual satisfaction and function during reproductive ages in Iran: a systematic review. Journal of Mazandaran University of Medical Sciences. 2017;27(153):146-62.

14. Fennell R, Grant B. Discussing sexuality in health care: A systematic review. Journal of clinical nursing. 2019;28(17-18):3065-76.

15. Taylor LD. All for him: Articles about sex in American lad magazines. Sex roles. 2005;52(3-4):15363.

16. Jones PW, Harding G, Berry P, Wiklund I, Chen WH, Leidy NK. Development and first validation of the COPD Assessment Test. European Respiratory Journal. 2009;34(3):648-54.

17. Pallant J. SPSS survival manual. McGraw-Hill Education (UK); 2013.

18. Bazarganipour F, Foroozanfard F, Taghavi SA, Hekmatzadeh F, Sarviye M, Hosseini N. Evaluation of female youth educational needs about reproductive health in non-medical students in the city of Qom. Journal of family \& reproductive health. 2013;7(2):67.

19. Afiyanti Y, Rachmawati IN, Milanti A. Evaluating sexual nursing care intervention for reducing sexual dysfunction in Indonesian cervical cancer survivors. Asia-Pacific Journal of Oncology Nursing. 2016;3(3):266.

20. Katibeh P, Inaloo S, Shokrpour N, Dashti H, Alavi Shoostari A. A survey of the suicidal attempt risk factors in adolescents in southern Iran. International journal of school health. 2018;5(1):1-8.

21. Bradley RPC, Friend DJ, Gottman JM. Supporting healthy relationships in low-income, violent couples: Reducing conflict and strengthening relationship skills and satisfaction. Journal of Couple \& Relationship Therapy. 2011;10(2):97-116.

22. Lalumière ML, Sawatsky ML, Dawson SJ, Suschinsky KD. The empirical status of the preparation hypothesis: explicating women's genital responses to sexual stimuli in the laboratory. Archives of Sexual Behavior. 2020;1-20.

23. Frederick DA, Lever J, Gillespie BJ, Garcia JR. What keeps passion alive? Sexual satisfaction is associated with sexual communication, mood setting, sexual variety, oral sex, orgasm, and sex frequency in a national US study. The Journal of Sex Research. 2017;54(2):186-201.

24. Basson R. Women's sexual dysfunction: revised and expanded definitions. Cmaj. 2005;172(10):1327-33.

25. Mosavi R. Review and compare the factors affecting marital satisfaction in three groups of physicians, employees and workers in Tehran. MSc Thesis]. Tehran: Tarbiyat Moallem University; 
2005.

26. Ziaee T, Jannati Y, Mobasheri E, Taghavi T, Abdollahi H, Modanloo M, et al. The relationship between marital and sexual satisfaction among married women employees at Golestan University of Medical Sciences, Iran. Iranian journal of psychiatry and behavioral sciences. 2014;8(2):44.

27. Samani S. Developing a family process scale for the Iranian families. Iranian Journal of Psychiatry and Clinical Psychology. 2008;14(2):162-8.

28. Rawhouser H, Cummings M, Newbert SL. Social impact measurement: Current approaches and future directions for social entrepreneurship research. Entrepreneurship Theory and Practice. 2019;43(1):82-115.

\section{Figures}

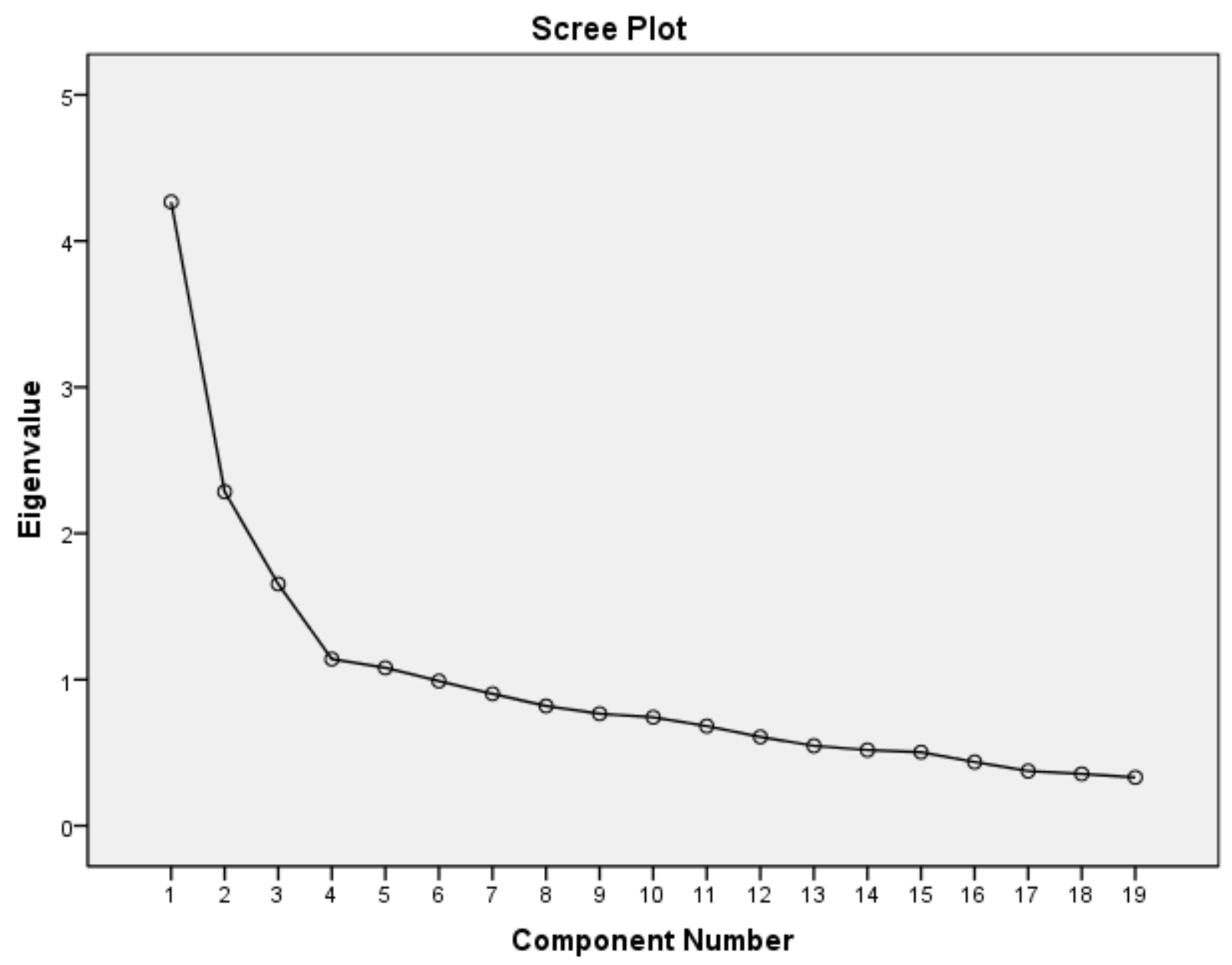

Figure 1

Scree plot. 


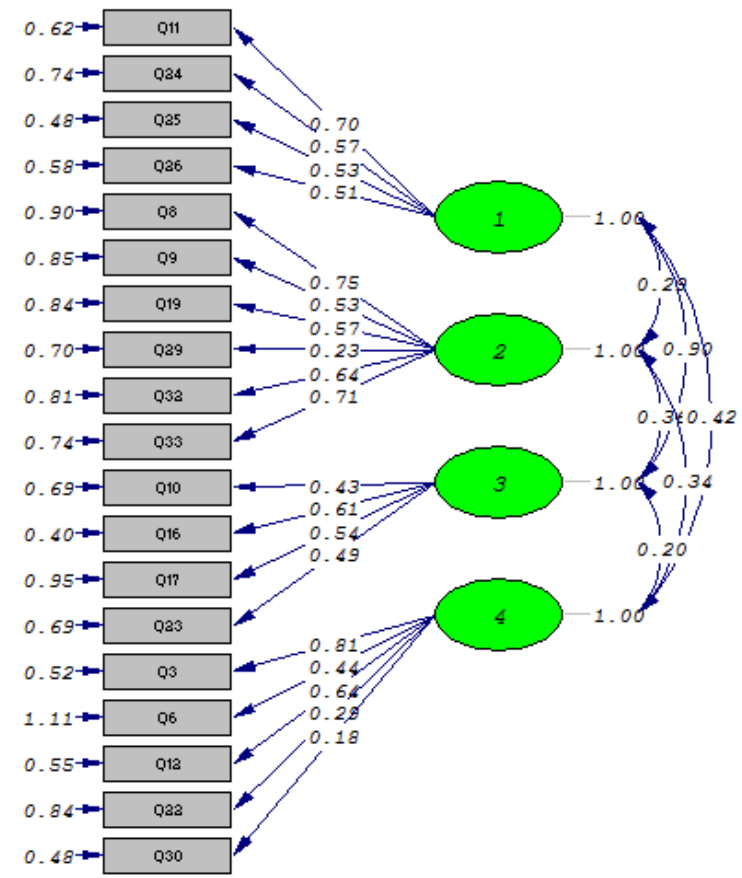

Chi-Square $=369.22, d f=146, P$-value $=0.00000, \quad R M S E A=0.084$

\section{Figure 2}

Structural diagram of factor analysis of sexual intelligence scale 


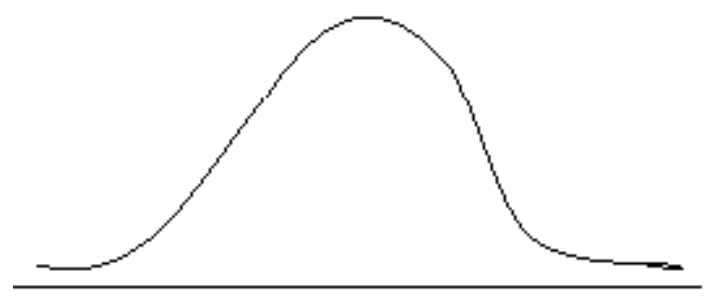

Figure 3

Normal distribution curve 